\title{
Rizo-Patrón, Rosemary, La agonía de la razón. Reflexiones desde la fenomenología práctica, Barcelona/Lima: Anthropos/Fondo Editorial de la Pontificia Universidad Católica del Perú, 20 I5.
}

\section{Luz AscáRATE}

Pontificia Universidad Católica del Perú

Según un prejuicio generalizado, las perspectivas sumamente teóricas se alejan del ámbito de la acción a tal punto que se las comprende como indiferentes a las problemáticas reales que dificultan la vida y convivencia de los seres humanos. No obstante, en más de un pensador, encontramos un discurrir teórico comprometido con las dimensiones prácticas, éticas, sociales y políticas de la vida de la humanidad, aunque no siempre de modo explícito. Rosemary Rizo Patrón nos entrega, en este libro -que junto a los dos anteriores publicados se alinea a los intérpretes del pensamiento de Edmund Husserl que defienden la unidad de la trayectoria del pensador a la luz de una lectura rigurosa de sus manuscritos-, una muestra de la integridad de su propio pensamiento. Este logra exitosamente encontrar respuesta a problemáticas que la han interpelado de cerca por el contexto social e histórico en el que ha desplegado su trayectoria, con base en la fenomenología trascendental del pensador que le ha servido de eje e inspiración: Edmund Husserl.

El título de esta obra hace referencia a la contienda que la razón libra al dirigirse sobre ella misma para definir su propia esencia o naturaleza. Con ello, apela al sentido originario de "agonía" (p. 7-8). El concepto de razón pura dio pie a diversos fundamentalismos que causaron grandes desastres en el terreno de la acción. Es por esto que las filosofías que se remiten a conceptos tales como los de fundamento, sujeto y razón han sido vigorosamente desacreditadas. La autora considera que, no obstante, dichas acusaciones no deberían opacar las concepciones legítimas de razón, fundamento y sujeto (p. 9). Desea pues reflexionar sobre estos conceptos metafísicos que se encuentran en disputa, 
en "agonía”, en la filosofía contemporánea. El eje de sus reflexiones se sitúa en el auténtico significado de la fenomenología trascendental de Edmund Husserl, y al aporte que, desde aquí, puede obtenerse para repensar las consecuencias éticas y políticas de los fundamentalismos, y las utopías políticas modernas y contemporáneas (pp. I0-II).

A pesar de que el libro está articulado de tal forma que sus capítulos pueden leerse independientemente, están agrupados de manera que pueda seguirse una secuencia argumentativa. Así pues, encontramos dos grandes partes. La primera se encuentra avocada principalmente al tratamiento de conceptos fenomenológicos referidos a la persona, la ética y la axiología, teniendo como eje el concepto de fundamentación racional, por lo que podría leerse como una introducción al pensamiento metafísico de Edmund Husserl. La segunda dirige dichos conceptos a la denuncia de los peligros violentos a los que conllevaría un carente o pernicioso uso de la razón. Expondremos, a continuación, los contenidos de cada una de estas partes.

La primera parte se titula "Dimensiones de la razón y constitución de la persona individual y colectiva”. Esta integra reflexiones en torno a los conceptos de fundamento, razón y sujeto desde la fenomenología trascendental de Edmund Husserl. Pero hace especial énfasis en aquello que compete a la praxis: el ámbito ético-axiológico y social (p. II). Así pues, en el primer capítulo, apoyándose en la cuarta y la quinta de las Meditaciones cartesianas, la autora muestra la vigencia de la filosofía fenomenológica trascendental, cuya fundamentación última no se apoya en la concepción de un sujeto trascendental solipsista, sino más bien en la naturaleza siempre abierta e inacabada de los análisis husserlianos, que transforman radicalmente los sentidos de "fundamentación" y de "sujeto trascendental". A partir de la "Cuarta meditación”, con la fundamentación genética se descubre la vida pre-reflexiva de la conciencia y se enmarca en el dominio de la facticidad trascendental que, para Husserl, constituye a la metafísica of filosofía segunda. Dicha perspectiva, para la autora, revoluciona la concepción de fundamentación última en tanto que abarca la totalidad de la experiencia teórica y práctica, y adquiere el carácter de indefinidamente abierta, intersubjetiva, descubridora de una autonomía y libertad absolutas (p. 32). 
El ejercicio de tal fundamentación depende de la subjetividad trascendental que apunta a la experiencia del sujeto desde punto de vista constituyente. En tanto hablamos de un sujeto encarnado e histórico al referirnos a un aspecto del mismo ser humano, podemos decir que la fenomenología es una antropología trascendental de nuevo cuño. Para afirmar esto, sin embargo, en el segundo capítulo, la autora sortea la relación entre la antropología y la fenomenología que, a primera vista, parecen irreconciliables según Husserl. Ello debido a que la antropología, al igual que la psicología, estaría referida al ser humano desde el punto de vista constituido y no constituyente (p. 34). No obstante, la fenomenología puede comprenderse, según la autora, como una antropología trascendental si tratamos al sujeto desde una perspectiva constituyente -aunando la aproximación fenomenológica estática con la genética.

Ahora bien, si nos referimos específicamente al ámbito de la voluntad y la estimación, que concierne a la ética y a la axiología, nos encontramos con dos periodos en la fenomenología de Husserl que corresponden al desarrollo estático y genético del método de su fenomenología trascendental, respectivamente (p. 65), como constatamos en el tercer capítulo. En ambos periodos, sin embargo, Husserl no olvida la base que todo formalismo tiene en el mundo de la vida intuitivo, lo cual ubica a Husserl a distancia de los objetivismos, incluso fenomenológicos, supuestos en una fundamentación formalista, ontológica o materialista de la ética (pp. 63-65). Para la autora, además, el método mismo de la fenomenología supone una dimensión ética. Por eso, en el cuarto capítulo, evidencia dicha dimensión presente en la reducción trascendental. Esta, lejos de ser una mera técnica epistemológica que perpetúa una filosofía de corte intelectualista y lejos de conducirnos a un subjetivismo egológico y solipsista, nos conduce, a partir de la actitud natural y por medio de un impulso teleológico voluntario, hacia "la más absoluta auto-responsabilidad racional" (p. 88). Esto solo puede darse si el sujeto se decide autónoma y responsablemente por un nuevo tipo de vida, "justificada absolutamente y expresada por una idea regulativa ético-cognitiva” (103). En los capítulos siguientes de esta primera parte, la autora va trasladando la preocupación ética presente en la fenomenología trascendental, al tema de la ciudadanía e identidad nacional, en un contexto tecnocrático, globalizado y multicultural. De este modo, va perfilándose el tratamiento que dará, en algunos capítulos de la segunda parte del libro, a problemáticas de corte nacional. 
En el quinto capítulo, la autora nos presenta el concepto de "actitud personalista". Esta se da cuando, al relacionarnos afectivamente con los otros, los consideramos metas prácticas de nuestras acciones voluntarias. Esta puede ser caracterizada, a su vez, como el tratar con las personas de nuestro mundo circundante considerándonos a nosotros y a ellos como sujetos libres. A partir de ahí, la autora revisa los conceptos de ciudadanía y esfera pública, en relación con principio de responsabilidad de Hans Jonas. Este principio nos compromete a asumir la responsabilidad de nuestros actos con respecto a un futuro que es cada vez menos probable predecir frente al cada vez mayor control técnico (p. I2I). Así mismo, establece una relación directa entre la responsabilidad y la posesión del poder, y defiende una posición de asimetría entre quien tiene mayor poder frente a su correlato ( $v$.gr. padres e hijos). Del mismo modo, atañe a la totalidad del cuerpo social de forma incondicional impidiendo la redistribución de la responsabilidad en tan solo algunos ciudadanos. Con ello dicho, la autora reflexiona acerca del tema concreto de los crímenes cometidos entre los años 1980 y 2000 en el Perú, investigados por la Comisión de la verdad y de la reconciliación (CVR). La responsabilidad del conflicto armado interno es de cada uno de los ciudadanos del país y nos interpela directamente: "Es un imperativo que tomen pronta conciencia de la propia responsabilidad” (p. 123). Solo de ese modo podrá darse paso al espacio ético de la ciudadanía.

En el sexto capítulo, se reflexiona acerca de la identidad nacional como telos de un estado político y de una praxis histórico-ética. Con ese fin, la autora se remite, de una parte, a la defensa de los comunitaristas por la pluralidad cultural y del individuo responsable en su contexto, $y$, de otra parte, a la defensa de los liberales por el universalismo de los derechos individuales que garantiza el Estado-nación independientemente de las distinciones culturales (p. 146). Busca mediar ambas posturas con el concepto fenomenológico de intersubjetividad, que nos permite comprender que el ser humano no es solo individuo, sino que es siempre persona intersubjetiva -que pertenece a una tradición y a una comunidad histórica-, para fundamentar el paso de la multiculturalidad a la identidad nacional a través de la intermediación de la inter-culturalidad (p. 149).

En la segunda parte de este libro, titulada "Del fundacionalismo moderno a la responsabilidad práctica”, nos encontramos con la crítica de la autora a los 
peligros de los irracionalismos o del erróneo encaminamiento de la razón. Así pues, en el séptimo capítulo, la autora analiza la relación que podría haber entre el fundacionalismo y el fundamentalismo. La filosofía, la cual tiene, desde Aristóteles y durante toda la Modernidad, la labor de dar fundamento, es, por principio, crítica y reflexiva, por lo que no podría constituir un cuerpo de doctrinas, un sistema ideológico dado o una cosmovisión (p. 153). En la época contemporánea, este pensamiento fundacional se muestra, según Ladrière -referente constante en esta segunda parte del libro-, en la metamatemática de Hilbert, el atomismo lógico de Russell y la fenomenología de Husserl. Ahora bien, la autora encuentra, en este capítulo, relación entre la tendencia fundacional del pensamiento occidental, criticada duramente por Hiedegger, y los fundamentalismos. Estos últimos son posiciones de ortodoxia, creencias ciegas, adhesión radical al fundamento en cuyo nombre se justifican abyectos crímenes (p. 163) y que no ponen en cuestión su fundamento. La autora apela aquí a la finitud y fragilidad del lenguaje político para subrayar la necesidad de "una deontología de la medida, mesura y respeto" (p. I76) frente a todo fundamentalismo. El octavo capítulo es el más largo de todo el libro, puesto que la autora trata aquí temas cuya dificultad exceden el ámbito de la reflexión filosófica y se dirigen al contexto nacional. Expone aquí el origen de la crisis de valores en la ontología reduccionista y el nihilismo propio del surgimiento de la época moderna, para hacer comprensible el acaecimiento de las éticas sobre el futuro. A partir de esta idea, distingue entre utopías patológicas y extremas, como, por ejemplo, la del pensamiento de Sendero Luminoso -la cual se alinearía con el concepto de fundamentalismo expuesto en el capítulo anterior-, y la idea de una esperanza responsable, respetuosa del principio de responsabilidad de Hans Jonas que la autora defiende frente a los peligros propios de las utopías patológicas.

En el noveno capítulo, la autora presenta la necesidad de replantear los problemas de la razón desde una perspectiva filosófica, la cual asumiría la raigambre finita de lo humano y podría replantear la oposición entre razón y violencia (p. 300), oposición que corre el constante riesgo de sucumbir. En el último capítulo de este libro, la autora reflexiona en torno al concepto de tolerancia situándose en el contexto del conflicto armado interno peruano y la labor de la CVR. En tanto el ejercicio del filosofar de la autora se mantiene abierto e inacabado, y revisa constantemente las conclusiones de sus análisis anteriores, se permite, en este capítulo, revisar nuevamente aquello que dijo 
en el séptimo capítulo (p. 304) acerca de la relación entre fundacionalismo y fundamentalismo. Sin embargo, en este texto escrito veinte años después, afirma que los fundamentalismos son esencialmente intolerantes y suponen una perversión de los fundacionalismos. Así mismo, señala que estos últimos tienen una versión que debe rescatarse: aquella que apele a una fundamentación última racional y a la idea de un sujeto auto-responsable, que asume las verdades "absolutas" como ideales asintóticos y que no renuncie al ideal universal de la razón; en otras palabras, una racionalidad tolerante a la que le sea inherente la tensión entre la finitud propia de la pluralidad de las perspectivas y la infinitud de su aplicación universal (p. 326). Es esto lo que encontramos en el caso de la CVR y en la propuesta fenomenológica de Edmund Husserl.

Por último, encontramos dos apéndices que sirven de complemento a los textos anteriores. El primero, "Persona y valor", desarrolla diversos temas fenomenológicos, por lo que su lectura sirve de lumbre para la comprensión de algunos conceptos de los textos de la primera parte, como los de intersubjetividad, razón práctica y razón valorativa. Así también, echa luces sobre el tema del mundo de la vida -con respecto a la ética, la axiología, la sociedad de la información y la educación-, y sobre la relación entre la crisis de la valores y el mundo de la política. El segundo, "Cultura y terror", reflexiona acerca de problemáticas políticas y sociales, por lo que complementa los textos de la segunda parte del libro. Encontramos aquí reflexiones que profundizan en temas tales como los de la utopía comunista, la acción política, la labor de la CVR, y la relación entre violencia y poder.

Podríamos afirmar, pues, que uno de los aspectos más valiosos de este libro radica en que puede ser considerado como una respuesta a la pregunta que interpela a la autora al inicio del octavo capítulo: "¿Cómo desarrollar un discurso filosófico responsable sobre el futuro y la esperanza en un mundo y una época signada por la crisis y -en muchos casos- por la desesperación?" (p. 177). Rosemary Rizo Patrón logra desarrollar este discurso responsable sin desembarazarse de una razón militante frente a la violencia que es consecuencia de los irracionalismos y los fundamentalismos. Este libro da muestra, de este modo, de una razón reflexiva y crítica, siempre atenta, frente a los posibles monstruos que aparecen en tiempos que se esfuerzan por hacerla soñar como pareciera sugerir su epígrafe inicial ("El sueño de la razón produce monstruos...", Francisco de Goya, 1799). 